\title{
Improving Electronic Banking in Ghana using USSD
}

\author{
Baffour Owusu \\ Sekyere \\ Department of \\ Computer Science, \\ KNUST, Ghana
}

\author{
Nuku Atta Kordzo \\ Abiew \\ Faculty of Computing and \\ Information Systems, \\ GTUC, Ghana
}

\author{
James Ben Hayfron \\ Acquah \\ Department of Computer \\ Science, KNUST, \\ Ghana
}

\author{
Christiana \\ Vormawor \\ Department of \\ Computer Science, \\ KNUST, \\ Ghana
}

\begin{abstract}
It is becoming evident that the use of electronic systems in performing transactions in modern day world deliver significant benefits to financial institutions. Payment systems are vital for financial institutions in any country. They enable the transfer of money and financial instruments. The desire for improved financial management service using Information Technology has transformed the banking sector and made better the various ways through which mobile phones have been used by costumers at their convenience to access and operate their accounts. The emergence of technological advancement has led to the introduction of mobile banking. The presented algorithms implemented using the USSD exploit a fine granularity synchronization strategy to significantly outperform existing strategies, particularly by improving the way electronic banking is carried out in Ghana. The research sketches a proof of correctness of these algorithms. This explains the use of model-checking to perform exhaustive verification within a limited application domain and also describe empirical tests performed on execution traces from an actual implementation. The researcher further enumerated new approaches that can be adopted in improving electronic banking
\end{abstract}

\section{General Terms}

Electronic Banking, Electronic Commerce.

\section{Keywords}

Banking, Electronic, Unstructured Supplementary Service Data, Technology

\section{INTRODUCTION}

Unstructured Supplementary Service Data (USSD) is a Global System for Mobile (GSM) communication technology that is used to send text between a mobile phone and an application program in the network. Applications may include prepaid roaming or mobile chatting. USSD is a simple and efficient data bearer that allows access to 100 per cent of mobile devices. From basic phones to smartphones without any need for mobile data access, USSD messages travel over GSM signaling channels and are used to query information and trigger services. While USSD is typically used by prepaid users to top up and manage their accounts, it is used for many other services worldwide. USSD is menu-driven, and therefore much more interactive than SMS, in pull or push mode (ability to push a menu to a mobile phone). USSD notifications and menus can dramatically improve the user's experience, giving you the ability to quickly and costeffectively send essential and useful alerts to engage in interaction and send important information. Whilst SMS has been used and abused, and often subject to spam and associated regulations, USSD is free from these issues. USSD adds trust to users both consumers for e-commerce and social media use. Unlike SMS, USSD notifications and menus are not stored on the device, which makes it safer for storing secure passwords or other sensitive information. This makes it an ideal bearer for Mobile Money, which allows people who typically do not have a bank account to make payments and purchases. The desire for improved financial management service using Information Technology has transformed the banking sector and made better the various ways through which mobile phones have been used by costumers at their convenience to access and operate their accounts. The emergence of technological advancement has led to the introduction of mobile banking. To this, customers prefer to effect transactions across various mobile device platforms thus bringing banking closer to their doorstep. As mobile banking continues to gain popularity, bankers and service providers continue to introduce new innovations to excite and attract new users and make it easier for the older customers to gain competitive advantage. Some of the exciting services offered to customers by the banking sector are payment of utility bills, transaction alerts, account balance enquiries and monthly statement notifications.

\section{LITERATURE REVIEW}

Information technology is the innovation that led to the technological drive and transformation of how business are conducted in recent times. Financial institutions and organizations have not been left out in this technological drive. This current change to mobile and internet banking has ICT as its core strategy. ICT sits at the center of any technological drive or strategy that are to be implemented by these financial institutions. According to Kofi Amoabeng of UT Bank in his retirement statements said "if you want to stay in business, implement all your strategies using ICT. It's only ICT that can keep you in this business where we have a lot of microfinances competing with banks". According to Laudon and Laudon [1] "ICT is accustomed to the physical devices and software that connects diverse computer hardware components and send data from one place to another." Also Harold and Jeff [2] contend that for financial service providers to maintain their viability in the years to come, modifications to their traditional operating practices must be forthcoming. They claimed that the banking industry and its operations are hindered by the reluctance of bank officials to embrace evolving technologies and incorporating them moving into the future.

Aig-Imoukhuede [3], opined that to deliver banking services toward a client and to be ready to offer assurance entry to them every time a client so requires, the on-line-real-time 
situation which represents the one significant amendment to banking operations over several years ought to be used. He stated that online banking services using the most easily accessible tools should be readily accessible to customers at all times so as to create the necessary conditions of familiarity and proximity between customers and banking services.

Ovia [4], said financial institutions have improved basically through the roll out and implementation of Information Technology in their banking operations and that the Information Technology budget in banking is considerably larger than pertains in any other industry. To this regards, a study was conducted on ascertaining the impact of on-line systems in facilitating internet banking. The findings of the study shows that banks now offer flexible and smooth ways of transactions at all branches irrespective of the account opening branch or location. He further stated that, though this development is on the better side, there is the need for more digitized operation as well as shuffling of cash and other forms using electronic transactions rather than using the manual and the paper system.

Woherem [5] also noted that, banks in Nigeria have performed better in their investment profile. He also stated that, banks in Nigeria as compared to other sectors of the Nigerian economy top the list of all the sectors that uses ICT to improve their business. Akensiro and Adetoso [6] also believes that computerized banking system has increased patronage of banks customers thereby impacting positively on the banking system in Nigeria increasing profitability, productivity and efficiency. To them computerize banking system should be adopted by all banks in Nigeria.

The studies mentioned above depicts the root by which technology has swayed the processes and operations of profitmaking banks in the world over a situation in which Ghana is no exception. However, banking can be improved further through the use of Unstructured Supplementary Service Data (USSD). No implementations of USSD on improving digital banking had been released. It is intriguing, however, that various procedures and tactics similar to USSD on bettering banking appear in peer-to-peer dispensed applications. It is worth knowing that, USSD is a menu-driven and therefore becomes much more interactive than SMS. USSD notifications and menu can dramatically improve the user's experience, giving you the ability to quickly and costeffectively send essential and useful alerts to engage in interaction and send important information. Whilst SMS has been used and abused, and often subject to spam and associated regulations, USSD is free from these issues. Another factor that drives USSD usage in emerging markets is the proliferation of services such as mobile money and valueadded services. This is often motivated by aspiration offering services such as Balance enquiry over USSD will appeal to customers who are attracted by this connected, social economic lifestyle.
Another point to note is that USSD is very important within emerging economies, where the cost to access data services is increasing. Despite the growth of smart-phone penetration and $3 \mathrm{G} / 4 \mathrm{G}$ coverage, the cost of data access is a very key factor in deciding how information is consumed. USSD has no limitations, so long as the mobile phone can make a call and send text, it can be used to access any USSD without incurring any cost from the Mobile Network Providers.

\section{METHODOLOGY}

\subsection{Introduction}

With the advent of Internet and its associated technologies, there is always the need to take a second look at our activities in the cyber world most especially with the use of smart devices like tablet, smartphones laptops and the likes. Security and privacy issues is always worth taking into consideration because the more we get wired and connected, the higher the risk of getting our privacy and security compromised. It is not uncommon that countries that have Information Technology integrated in their various sectors of their economy seem to be doing very well in terms of development and financial stands.

This is no different for institutions like banks and other financial corporations. As such taking advantage of Information Technologies is a must for all financial institutions. Currently in Ghana, Mobile Network Operators (MNOs) such as MTN, Vodafone, Tigo and Airtel are collectively not taking full advantages associated with their infrastructure as far as services associated with banks and financial institutions are concerned. In any case the few MNOs that are trying to implement these infrastructures do not do so effectively thereby still leaving room for improvement. This is evident in the greater number of mobile wallets than bank accounts. It is also an evidence that, in each of these markets, mobile payment platforms are being leveraged to offer other financial services such as savings and credit to customers.

The financial reward associated with these technology proves the worth in implementing them. Moreover MNOs can pull a lot of competitions among regulators in the country due to the fact that MNOs have competitive edge with these financial institutions and other MFS providers through provision of Mobile Payment systems, but MNOs also own key communication infrastructure required to provide mobile payments. In this research, a new way of improving electronic banking and sustaining the interest of customers at a low cost with a better customer satisfaction will be assessed. However the underlying standard for the implementation of this technology is realistic. This research also gives a novel implementation of the Unstructured Supplementary Service Data model using java. 


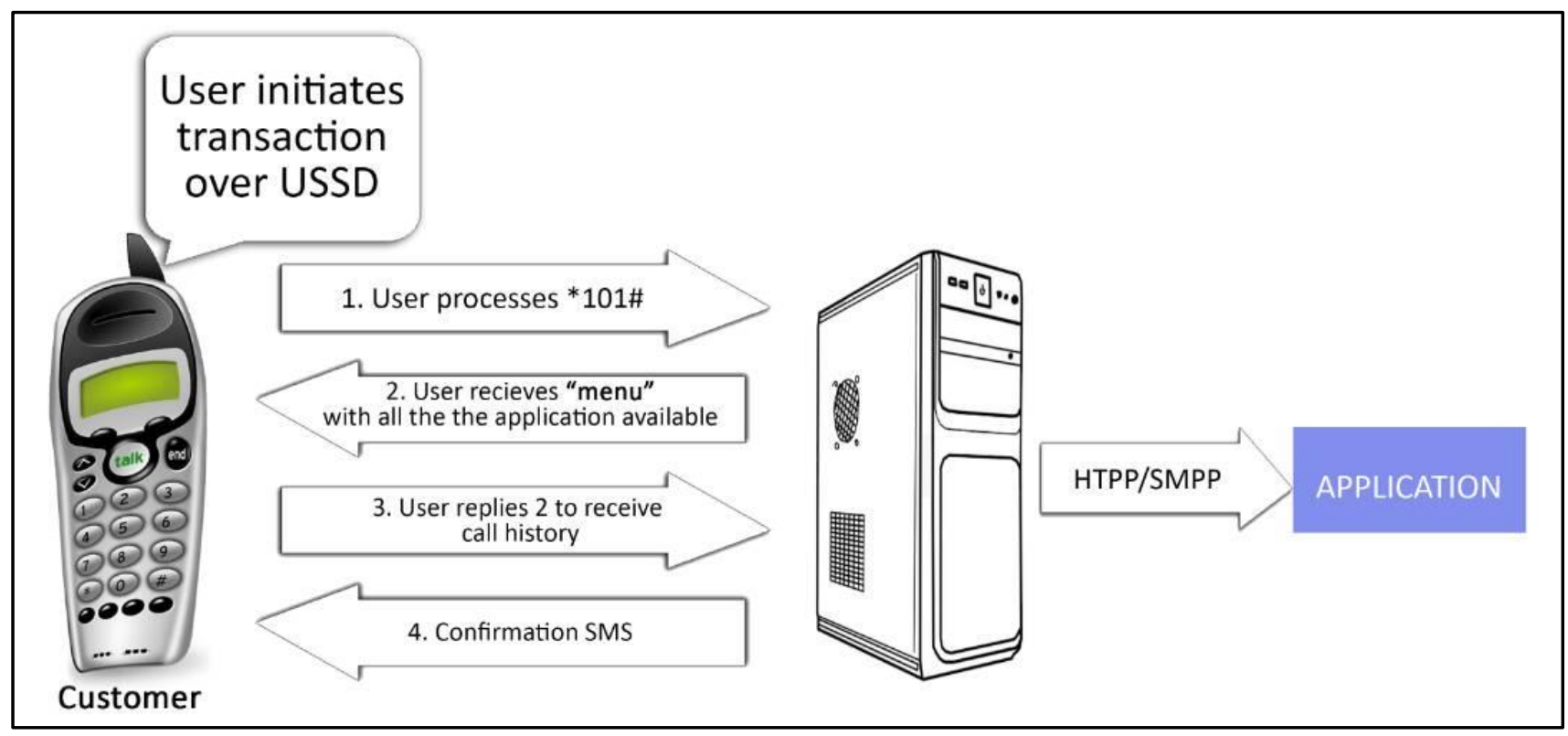

Fig 1: USSD Call Flow Algorithm

A typical USSD call flows as illustrated in the figures is defined as below:

i. USSD based application appears when user presses *101\#.

ii. User based browser with menu options for bill charges, history and other self-centered subscriptions

iii. IVR based with numerical options for call history

iv. Call logs from USSD server

\section{SYSTEM IMPLEMENTATION}

The testing of the system involved conducting an evaluation of the various components that make up the system. This has been done to ensure that the system that been developed performs to satisfaction and satisfied all requirements. The evaluation has largely been based on functional requirement of the system and non-functional requirements. The modules of the systems were tested during the loading and execution of the system in hierarchical order.

Table 1. Modules of the System

\begin{tabular}{|c|l|c|}
\hline \multicolumn{1}{|c|}{ Module } & Actors \\
\hline 1. & User Authentication & Customers, Bank trustee, MNOs \\
\hline 2. & Balance Enquiry & Customers, Bank trustee, MNOs \\
\hline 3. & Fund Transfer & Customers, Bank trustee, MNOs \\
\hline 4. & Bill Payment & Customers, Bank trustee, MNOs \\
\hline 5. & Mini Statement & Custee, MNOs, Third party companies \\
\hline
\end{tabular}

\subsection{Authentication}

Every intended user of the system has to be authenticated. To start with, the user dials the dedicated USSD code, in this case *123\#. Fig 2 shows the user dialing the code. This is done from a registered GSM Phone. Otherwise no further access will be granted. The rest of the entire authentication process is illustrated in Fig 3. 


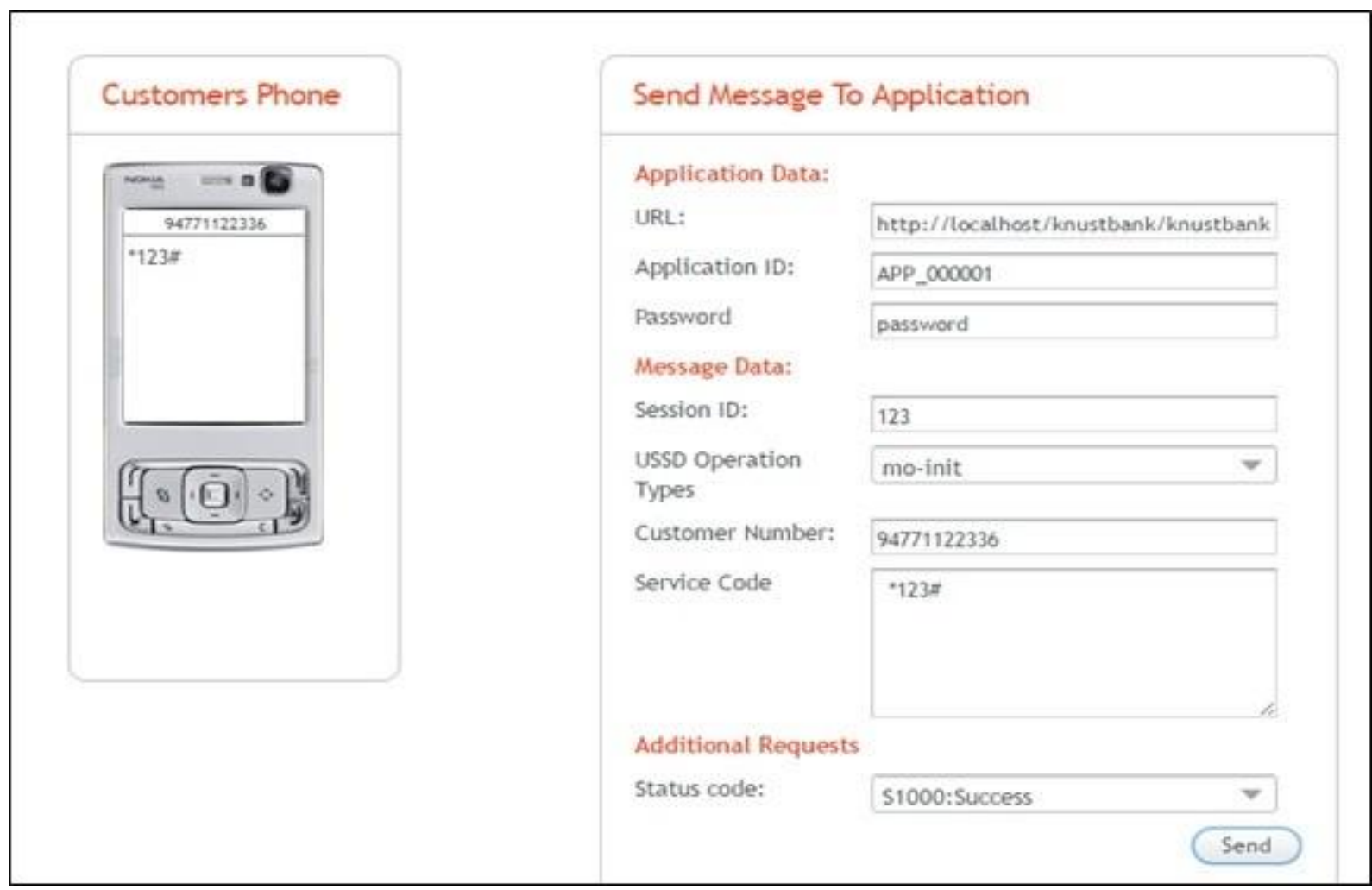

Fig 2: User entering the dedicated USSD Code

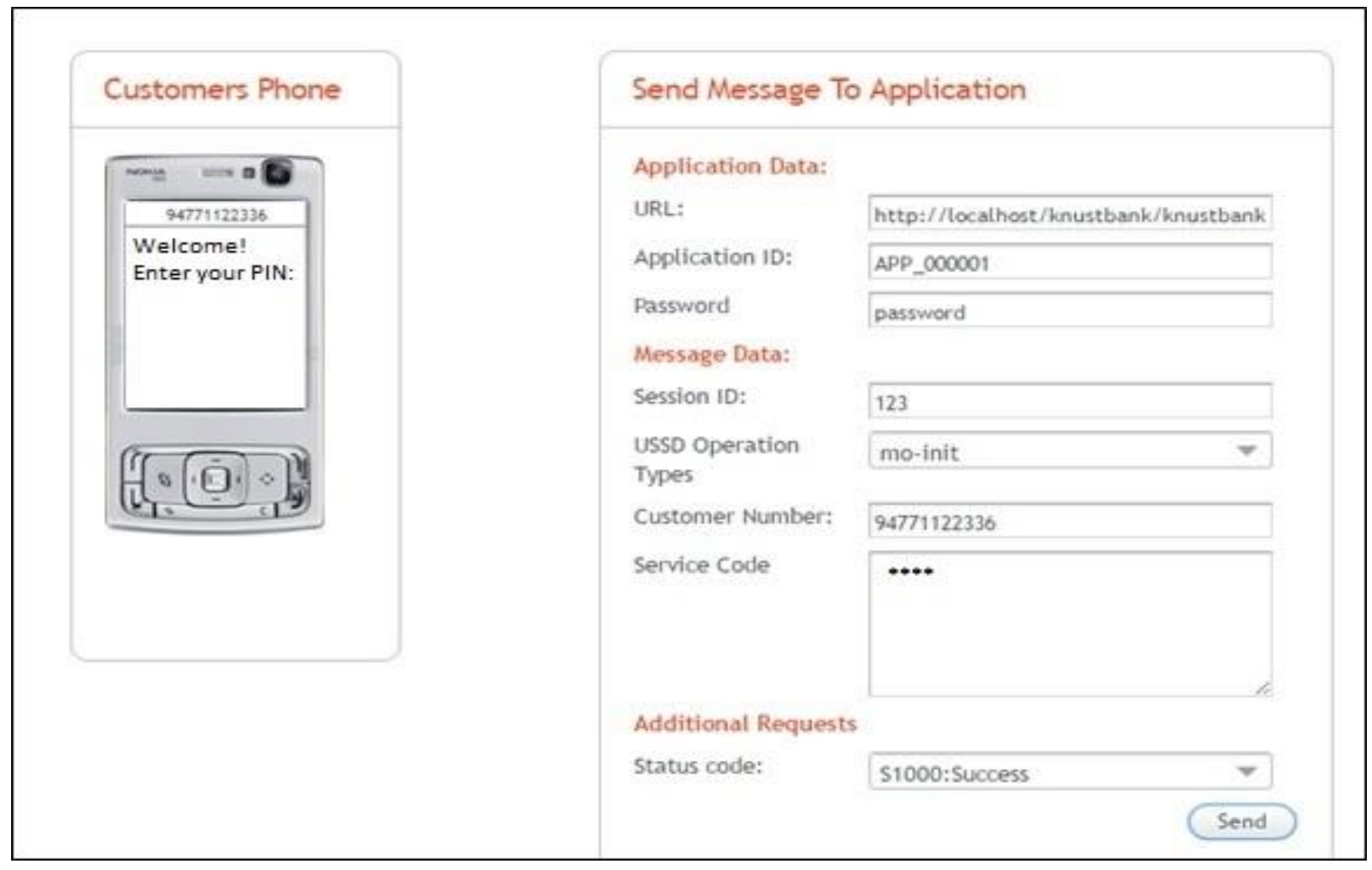

Fig 2: Prompt requiring the user to enter the PIN

\subsection{Balance Enquiry}

The balance enquiry functionality allow access to and display a customer or an account holder's current account balance. A user would have to select an account type such as savings, current, fixed deposit or other according to how a user's account type was setup. Generally, most banks in Ghana operate mainly with two account types-Savings and Current Accounts. 
Accessing a customer's account balance requires the user to perform the following steps:

1. Select an account type option from the menu (such as Savings, Current, Fixed Deposit or Other)
2. Enter a Customer or User's Account Number and Press OK / Send

3. Displays Current Account Balance

\section{Dialog}

\section{IdeaMart Simulator}

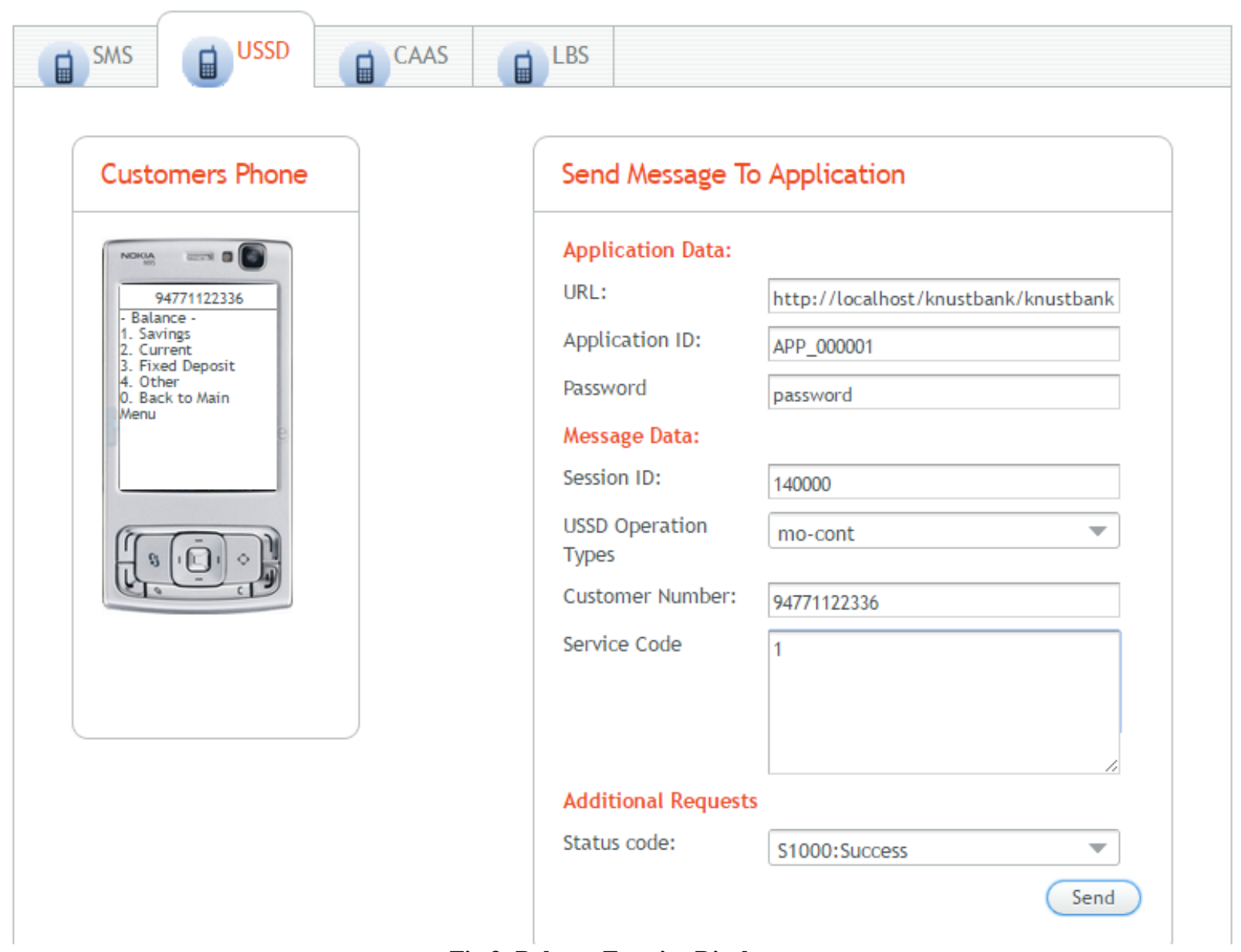

Fig 3: Balance Enquiry Display

\subsection{Fund Transfer Module}

The Fund Transfer process can also be accessed directly from the main menu after a successful authentication. The Fund Transfer process of the proposed systems has been designed such that it takes three steps to enable the user to have ample time to perform all tasks required of the process. This is because the live session that is created between the user's phone and the GSM service provider cannot be extended for very long. The sessions are capped at after a reasonable time to avoid a possible denial of service on the servers of the GSM network provider. These three (3) basic steps made it possible to virtually move cash from one account to another.

The first step involves the sender entering his or her account number details. The system then performs a background check on the account to check whether it exists in the bank's database. If it exists the system moves to the next step.
The next step involves the user entering the account number of the receiver. The last step involves the user specifying the amount he or she wants to transfer. The system performs a background check on the proposed amount against the users' current balance. It then authenticates the process after the user clicks on the send button and the fund will be transferred from the user's account to the receiver's' account. However, this process will only be successful if the supposed account number of the receiver is registered with the bank. The system performs validation on the recipient account number and if otherwise, the appropriate error message is displayed. 


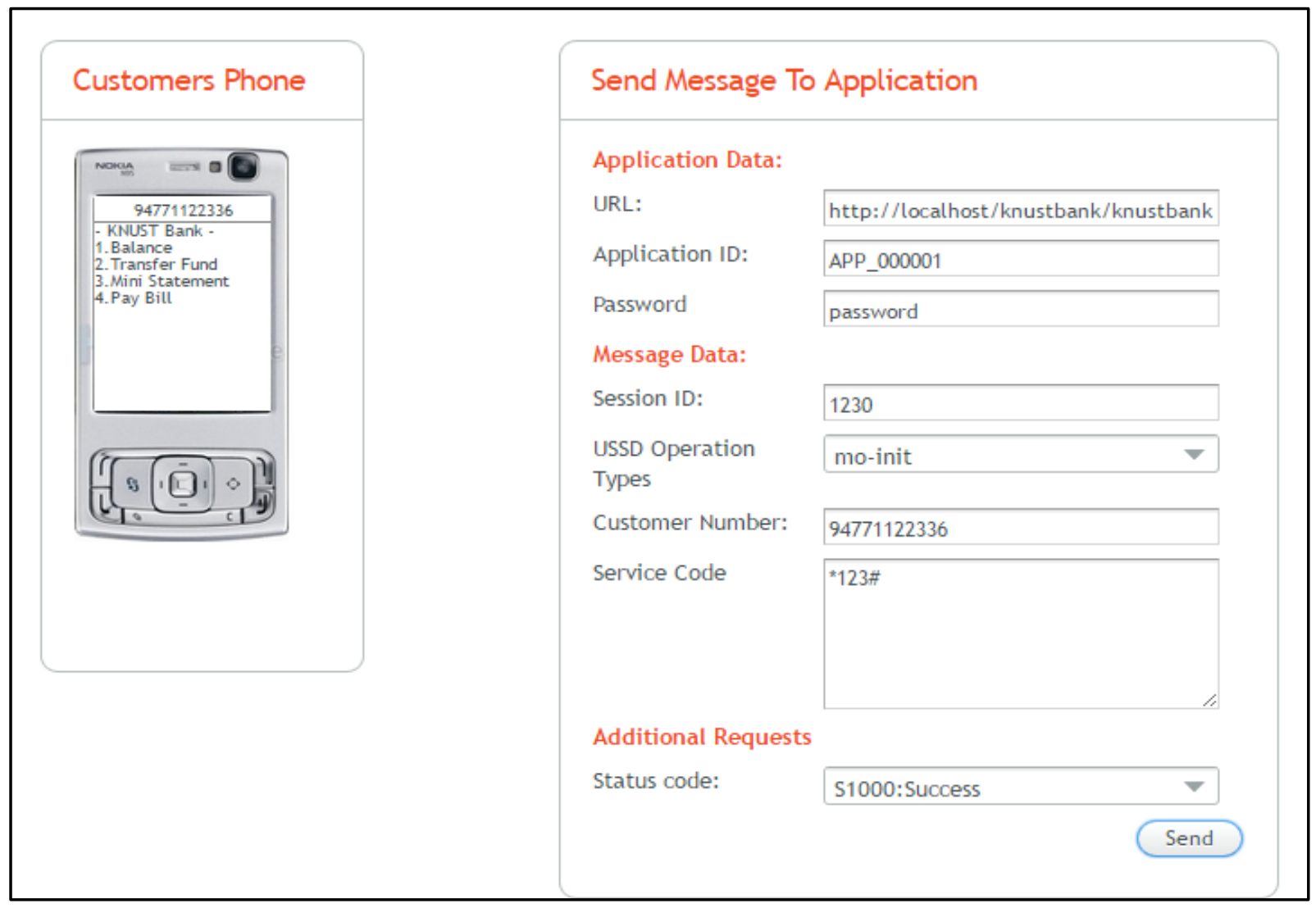

Fig 4: Main Menu

\section{CONCLUSSION}

5.1 The study reveals a new execution of mobile banking using USSD with mobile phones operated on the GSM platform was presented, analyzed and discussed. USSDs are one of the most basic techniques used in the designing of programs that operates on the GSM platform, and so a simple and effective non-blocking, robust implementation could serve as the basis for many improvement in the field of technology and banking. The study is purported to present a novel implementation of electronic banking differently from the existing techniques used by most banks using the available mobile network infrastructure. The proposed systems exploit a fine granularity synchronization strategy to significantly outperform existing algorithms, particularly for performance of basic banking transactions.

\section{REFERENCES}

[1] Laudon, K.C, Laudon, J.P. 2003. Management Information Systems:Managing the Digital Firm,Upper Saddle River, NJ: Prentice Hall.
[2] Harold, B. Jeff, L.1995. Don't Let Technology Pass You By, ABA Banking Journal, Box 986, Omaha, NE, page 73.

[3] Aig-Imoukhuede.2003.The Role of Information Technology on Commercial Banks in Nigeria. Ibadan

[4] Ovia, J. 2001. Financial Information and Communication Technolgy: Opportunities and Constraints at the African IT exhibitions and Conferences venue held at the Eko le Meridien Hotel Lagos.

[5] Wohorem E. 2000. Information Technology in the Nigerian Banking Industry, Spectrum Ibadan.

[6] Akensiro, S.A, Adetoso J.A. 2016. The Effects of Computerised Accounting System on the Performance of Banks in Nigeria. Journal of Economics and Sustainable Development, Vol.7, No.14, 2016.

[7] Ovia J. 2005. Enhancing the Efficiency of the Payment System in Nigeria, CBN Bullion, Vol. 29(1). Page 8- 18. 